\title{
Experience and overall satisfaction of foreign patients with the health care services received in Latvia
}

\author{
Daiga Behmane $^{1}$, Anda Batraga $^{2}$, Mara Greve $^{3}$, and Didzis Rutitis ${ }^{4}$ \\ ${ }^{1}$ Institute of Public Health, Rīga Stradinsš University, Riga, Latvia \\ ${ }^{2}$ University of Latvia, Riga, Latvia \\ ${ }^{3}$ The Statistics Unit, Rīga Stradiņš University, Riga, Latvia \\ ${ }^{4}$ School of Business and Finance, Riga, Latvia
}

\begin{abstract}
The study evaluates foreign patients' experience and satisfaction in relation to the health care received in Latvia. By applying the gap model of service evaluation, the study reveals the difference between expected and received service outcome in Latvia, and draws conclusions about the importance of individual and patient experience factors related to the overall patient satisfaction. The study concludes that in all groups of factors matrix proposed in the study: (1) general travel or destination factors; (2) communication factors; (3) factors related to the choice of service and (4) factors related to the choice of health care institution, patients evaluated the perceived health care outcome higher than the expected outcome. The results of the study lead to the conclusion that there is a significant gap in foreign patients' knowledge regarding the possibilities of receiving a highlevel health care service in Latvia. The results also reveal the most important determinants of patient experience and related satisfaction.
\end{abstract}

\section{Introduction}

Health care is a globally growing sector that contributes to the growth of global gross domestic product (GDP) mainly due to trends in the development of medical technologies and population ageing, including longer life expectancy that leads to an increasing demand for health services. Limited public resources in the health sector and growing expectations stimulate a change in the pattern of consumer behaviour, which is related to the economic, social, psychological and cultural aspects of consumer behaviour and stimulate the role and empowerment of consumers in selection of health services, including cross-border services $[1,2]$.

Opening up the Latvian health sector to foreign consumers would mean increasing the competitiveness of service providers and services offered at international level, as well as an efficient and attractive provision of health services to local patients and a developed common market for services.

Currently, the country does not have official statistics on the volume of services provided to foreign patients. Information gathered by associations of export related medical institutions, shows that the number of services provided to foreigners is increasing significantly year after year [3]. At the same time, according to the European Court of Auditors' report, the number of patients receiving cross-border health care services, provided under EU Directive 2011/24/EU and Regulation (EC) No. 883/2004 (officially registered 
through the national contact point) in Latvia, is one of the lowest among EU Member States. In 2016 such patients were only 167 or $0.08 \%$ of the total 213096 patients, while in Estonia the number was 10044 , and 369 patients in Lithuania [4]. At the same time, publications highlight that cross-border healthcare can pose significant threats to patient safety and rights, and the debate on its impact on national healthcare systems is evolving [5,6]. Therefore, healthcare systems should pay more attention to the realization of patient values, which need to be further explored.

The aim of the study is to evaluate the experience and overall satisfaction of foreign patients with the health care services received in Latvia. It based on the authors' developed matrix of factors related to (1) general travel factors; (2) communication factors; (3) factors related to the choice of health care service provider and (4) factors related to the choice of health care service. The context of patient-centred care and specifics of cross-border was taken into account in the development of the factor system [7-9].

\section{Methods}

The study based on quantitative approach by conducting a survey of foreign patients in eight Latvian medical institutions in the period from October 2018 to March 2019. The profile of medical institutions covered diagnostic and treatment services and they were chosen on a voluntary basis representing export oriented health care providers. The questionnaire was completed by 217 respondents, 4 questionnaires were found invalid, 213 respondents' questionnaires were used for the analysis. The experience of patients was evaluated by assessing the gap between the expected and perceived value of the service by applying the service quality "gap" assessment [10] and a modified SERVQUAL questionnaire approach [11].

Statistical analyses were performed using IBM SPSS statistics for Windows, version 23.0. Categorical data were expressed as percentages. Perceived and expected outcome in each question was compared with Wilcoxon test. To evaluate the total expected and perceived outcome coefficients were calculated for all questions and questions in factor groups as a sum of rating in answers divided by the sum of maximum possible rating. Coefficients did not follow normal distribution (Shapiro-Wilk test, $p<0.05$ ), and Mann-Whitney U test was used to compare groups. Correlation between overall satisfaction and factor groups of perceived outcome was assessed with Spearman's rank correlation coefficient.

Two-step cluster analysis of the results was carried out in order to characterise and distinguish consumer groups with satisfaction unifying characteristics (more and less satisfied) in relation to gender, residence status, number of days spent in the institution and age.

\section{Results and discussion}

\subsection{Design and structure of the questionnaire}

The questionnaire was developed according to the matrix of factors developed in the context of patient-centred care approach and specifics of cross-border care related to patient safety and service quality assurance. The questionnaire included 15 questions aimed at studying the experience and one concluding question related to overall satisfaction with the service received (see Table 1).

The second part of the questionnaire included questions to find out the socio-demographic parameters of patients, travel details, information and communication channels and language and other aspects related to the choice of the particular service. 
Table 1. Matrix of factors for evaluating the experience and satisfaction of foreign patients.

\begin{tabular}{|c|c|c|c|}
\hline Factor group & Factor & Quality Dimension & Question no. \\
\hline \multirow{3}{*}{$\begin{array}{l}\text { 1. General travel } \\
\text { factors }\end{array}$} & 1.1 Geographical accessibility & Tangibility & 1 \\
\hline & 1.2 Safety of the destination & Assurance & 2 \\
\hline & $\begin{array}{l}\text { 1.3 Reputation and image of the } \\
\text { destination }\end{array}$ & Assurance & 3 \\
\hline \multirow[t]{4}{*}{$\begin{array}{l}\text { 2. Communication } \\
\text { factors }\end{array}$} & $\begin{array}{l}\text { 2.1. Positive first impression on } \\
\text { health care institution }\end{array}$ & Reliability & 4 \\
\hline & $\begin{array}{l}2.2 \text { Full information about the } \\
\text { provision of the service }\end{array}$ & Reliability & 5 \\
\hline & $\begin{array}{l}\text { 2.3 Kindness and helpfulness of } \\
\text { personnel }\end{array}$ & Empathy & 6 \\
\hline & $\begin{array}{l}2.2 \text { Full information about the } \\
\text { continuity of the service }\end{array}$ & Responsiveness & 9 \\
\hline \multirow{4}{*}{$\begin{array}{l}\text { 3. Factors related to } \\
\text { the choice of health } \\
\text { care institution }\end{array}$} & $\begin{array}{l}2 \text { Full information about the costs } \\
\text { of the service }\end{array}$ & Responsiveness & 7 \\
\hline & 3.2 Safe environment & Assurance & 8 \\
\hline & $\begin{array}{l}\text { 3.3 Innovative technologies in the } \\
\text { provision of services }\end{array}$ & Tangibility & 12 \\
\hline & $\begin{array}{l}\text { 3.4 Transport service to/from the } \\
\text { institution }\end{array}$ & Tangibility & 15 \\
\hline \multirow[t]{4}{*}{$\begin{array}{l}\text { 4. Factors related } \\
\text { to the choice of the } \\
\text { health care service }\end{array}$} & $\begin{array}{l}\text { 4.1 Exchange of medical } \\
\text { information with the physician in } \\
\text { the home country }\end{array}$ & Assurance & 10 \\
\hline & 4.2 Relevant price & Tangibility & 11 \\
\hline & 4.3 Timely service provision & Responsiveness & 14 \\
\hline & $\begin{array}{l}4.3 \text { Availability of medical } \\
\text { records }\end{array}$ & Reliability & 13 \\
\hline Patient experience & Overall satisfaction rating & & 16 \\
\hline
\end{tabular}

Source: developed by the authors.

Patients were asked to rate aspects related to receiving the service according to their expected and received result. Each aspect was evaluated according to a 5-point Likert scale. The questionnaire was tested in a pilot study, during which it turned out that the population of foreign patients is heterogeneous and, therefore, two categories of respondents were identified - "non-residents" and "residents", and question 6 of the questionnaire was adjusted, by adding an additional answer "lives in Latvia". The resident group included foreign patients staying in Latvia under a temporary residence permit (embassy employees, students, etc.), but who are not considered permanent residents of Latvia. Cronbach's alpha of 15 questions was found to be 0.89 for the expected outcome and 0.85 for the received outcome.

\subsection{Characteristics of demographic and socio-economic parameters of patients, choice and the service received}

Of the respondents, $56.3 \%$ were females and $47.7 \%$ males. The majority (70.4\%) of all respondents were at working age - from 30 to 65 , but $22.5 \%$ of the respondents were under the age of 30 . Only $7.0 \%$ were over the age of $65 ; 85.7 \%$ of respondents were not residents 
of Latvia (25.0\% from Ukraine, 21.7\% from the UK, 8.3\% from Estonia; other countries represented: Germany, Lithuania, Italy, Belarus, Sweden, Finland, Norway, Netherlands, Kyrgyzstan, France, and USA).

The most frequently used type of medical services was surgery $(21 \%)$. The second most popular was radiation therapy (18\%), and the third was dentistry (16\%), which shows that foreign patients choose technologically sophisticated medical services in Latvia with highly added benefit, which cannot be provided by health care institutions in their country, thus pointing out certain shortcomings in creating a patient-centred system.

More than half of all respondents (57.7\%) spent only one day in a medical institution while receiving services, about a fifth (23.9\%) spent more than 5 days and a slightly smaller proportion of respondents (18.3\%) spent two to five days in the medical institution.

Having analysed various communication factors, the study concludes that the most frequently used languages of communication at the time of receiving the service were English $(63.4 \%)$ and Russian (47.9\%). Most of the participants decided to communicate by phone $(85.9 \%)$, in addition to them another $11.3 \%$ used Skype or video calls, $62.0 \%$ of the participants chose email for communication.

The study shows that only $9.9 \%$ of all respondents did not have access to the service they received in Latvia in their country of residence (radiation therapy, surgery, ophthalmology, oncology, neurosurgery and dentistry were among the identified services). Dissatisfaction with the organization of the service $(43.6 \%)$ and dissatisfaction with the price of the service $(27.3 \%)$ are mentioned as possible obstacles why the service was not used in the country of residence. Respondents, who identified other obstacles (25.5\%), mentioned low quality of service, lack of confidence in doctors and old equipment. In only $18.1 \%$ of cases, the service in the country of residence was not covered by the state, which shows that despite the service being paid for by the government in the country of residence, the service organization prevails as a choice factor.

Respondents most often found out about the possibility of receiving medical services in Latvia via the Internet (40.8\%), from family or friends' recommendations (35.2\%), and also thanks to information provided by a doctor (32.4\%). $14.1 \%$ of patients indicated that they are regular customers. Printed information and broker services are less important in terms of information channels.

One of the key issues in cross-border health care is the transfer of patient's medical data to the patient's doctor in the country of origin to ensure the best possible quality of future treatment process. Regarding the need to provide information about the service received, slightly more than half of the respondents $(59.2 \%)$ noted that they are not required to share the information with their doctor in the country of origin. The author concludes that the most preferred format for obtaining medical data was email (83.1\%), although a relatively large percentage of respondents prefer to receive data in print format $(45.1 \%)$ as well.

The costs were most often covered by the recipients of medical services themselves (85.9\%), $16.9 \%$ of respondents mentioned the support of insurance companies, while in only $5.6 \%$ of cases the costs were covered by the health system of country of origin. Despite the choice of high level of tertiary services, most patients did not require permission from their doctor in the country of origin; such permission was necessary only for $7.0 \%$ of respondents. The need for permission was more often associated with staying in hospital for at least one night $(75.0 \%)$, as well as because of specialised and expensive procedure (50\%), less often with the quality and safety of service $(25 \%)$.

Analysing consumer experience in the exchange of medical information and the necessity of medical documentation, the author concludes that $40.8 \%$ of respondents had to send their medical data to the medical institution in Latvia before receiving service. It generally shows that Latvian medical institutions are partly interested in the availability of patient's data, and 
that mostly applies to radiotherapy and surgery services where the patient is required to stay in medical institution for more than one day ( 2 and more).

\subsection{Evaluation of patient experience and overall satisfaction}

The study results show that in all questions patients rated the perceived outcome higher than the expected outcome (see table 2, score in column 5), which reflects the high level of patient satisfaction (see Table 5). The level of satisfaction with medical care demonstrates the fulfilment of the patient's expectations. The author believes that the patient-centred approach, which was recognized as important by many authors analysed in the theoretical part, should now serve as an indicator of the high quality of the medical services provided.

The lowest expected outcome (score of "5" in less than $60 \%$ of cases) was given to general travel factors - the geographic accessibility of the service provider (58.6\%), as well as the visibility and image of the country $(59.4 \%)$, followed by communication factors (information on the website) (66.7\%), acceptability of the price of the service (64.2\%). Only $48.1 \%$ of patients expected the provision of transportation (factor in choosing medical institution).

The difference of all factor evaluations (positive gap) between the values of expected and perceived results is statistically significant (Wilcoxon test, $Z=-5.328, p<0.001$ ). This shows that the respondents, coming to and receiving health care services in Latvia, remained more satisfied than initially expected. The score obtained in all questions exceeds expectations, especially among male patients, where the increase in the coefficient is higher for men (median: 0.03, Q1-Q3: 0.00-0.09) than for women (median: 0.00, Q1-Q3: 0.00-0.03), Mann-Whitney U test, $U=3654.0, p<0.001$.

The differences in the evaluation coefficients of all factors are shown in Table 3.

The study reveals that Latvia is not a well-known destination for health care services and it points out to the shortcomings of marketing and communication factors at the macro level. In view of the specific nature of the health care factor, the results of the study indicate that there is also the need to improve the availability of mezzo-level information on health services available in Latvia. It corresponds to the conclusions in other studies $[12,13]$ on incomplete provision of international requirements and health system level specific restricting factors at the mezzo level, which could contribute to the visibility of Latvia as a travel destination for cross-border health care services.

As the factors with the highest performance value ("4" and " 5 " according to the Likert scale) foreign patients ranked communication factors $-86 \%$ of respondents, followed by destination availability, security and reputation $-81 \%$, service choice and service provider selection factors - respectively $79 \%$ and $78 \%$ of respondents. The highest rated factor is the kindness and responsiveness of staff (96\%), which indicates a significant motivation of medical staff in service-oriented health care institutions.

Calculation of the correlation between patients' overall satisfaction with the services received and the patient experience related groups of factors shows that general travel factors most closely relate to patient satisfaction. They are followed by communication factors and health care service choice factors (see Table 4). The statistical analysis shows that satisfaction rates correlate statistically significantly $(p<0.001)$ with all groups related to the perceived outcome.

Two-step cluster analysis characterise and distinguish consumer groups - more and less satisfied in relation to gender, residence status, number of days spent in the institution and age (see table 5). Two clusters were identified, one with 45 participants $(34.1 \%)$ and the other with 87 participants $(65.9 \%)$. The silhouette coefficient (0.5) indicates an average clustering quality. 


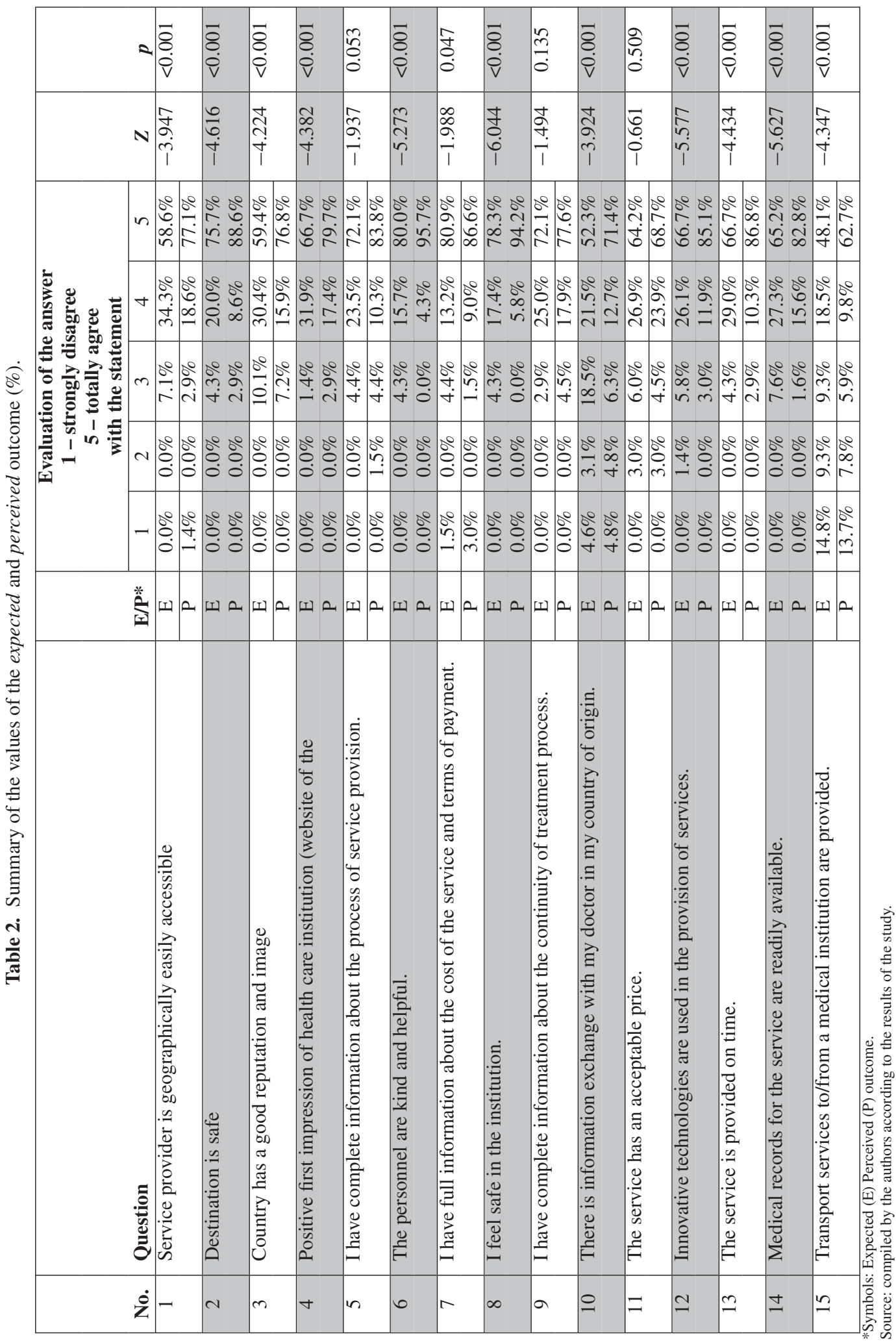


Table 3. Differences in the values of all factors in the total expected and perceived outcomes for women and men.

\begin{tabular}{|l|l|l|}
\hline & Coefficient of the total outcome of all factors, Median (Q1-Q3) \\
\hline & Expected outcome & Perceived outcome \\
\hline Men & $0.85(0.80-0.92)$ & $0.93(0.85-1.00)$ \\
\hline Women & $0.93(0.85-0.98)$ & $0.93(0.90-0.98)$ \\
\hline \hline
\end{tabular}

Source: compiled by the authors according to the results of the study.

Table 4. Factor group correlation with the overall satisfaction of foreign patients.

\begin{tabular}{|l|c|c|c|}
\hline $\begin{array}{l}\text { Perceived outcome, } \\
\text { factor group }\end{array}$ & Median $\left(\mathbf{Q}_{\mathbf{1}}-\mathbf{Q}_{\mathbf{3}}\right)$ & $\begin{array}{l}\text { Spearman's correlation with } \\
\text { the answer in question no. 16 } \\
\text { (completely satisfied) }\end{array}$ & $\boldsymbol{P}$-value \\
\hline General travel factors & $1.00(0.93-1.00)$ & 0.490 & $<0.001$ \\
\hline $\begin{array}{l}\text { Communication } \\
\text { factors }\end{array}$ & $1.00(0.95-1.00)$ & 0.439 & $<0.001$ \\
\hline $\begin{array}{l}\text { Factors related to the } \\
\text { choice of health care } \\
\text { institution }\end{array}$ & $1.00(0.90-1.00)$ & 0.377 & $<0.001$ \\
\hline $\begin{array}{l}\text { Factors related to the } \\
\text { choice of the health } \\
\text { care service }\end{array}$ & $0.95(0.90-1.00)$ & 0.427 & $<0.001$ \\
\hline
\end{tabular}

Source: compiled by the authors according to the results of the study.

Table 5. Characteristics of patients in both clusters according to their unifying features.

\begin{tabular}{|l|l|l|l|}
\hline & Cluster 1 & Cluster 2 & p-value \\
\hline $\begin{array}{l}\text { Gender } \\
\text { men } \\
\text { women }\end{array}$ & $73.3 \%$ & $34.5 \%$ & $<0.001$ \\
\hline $\begin{array}{l}\text { Residence status } \\
\text { residents }\end{array}$ & $26.7 \%$ & $65.5 \%$ & \\
$\quad$ non-residents & $21.4 \%$ & $0 \%$ & $<0.001$ \\
\hline Age & $78.6 \%$ & $100 \%$ & \\
$\quad<30$ years & $33.3 \%$ & $20.7 \%$ & 0.259 \\
30-65 years & $60.0 \%$ & $69.0 \%$ & \\
$\quad>65$ years & $6.7 \%$ & $10.3 \%$ & \\
\hline $\begin{array}{l}\text { The number of days in the institution } \\
\text { 1 day }\end{array}$ & $66.7 \%$ & $41.4 \%$ & 0.018 \\
2-5 days & $6.7 \%$ & $17.2 \%$ & \\
$\quad>5$ days & $26.7 \%$ & $41.4 \%$ & \\
\hline
\end{tabular}

Source: compiled by the authors according to the results of the study.

Participants in the second cluster gave a more positive assessment. They also had a statistically significantly smaller difference between the coefficients of the perceived and expected assessment (Mann-Whitney test, $U=1557.0, p=0.046$ ). Completely satisfied in the second cluster were $96.6 \%$ of the participants, while completely satisfied in the first cluster were $73.3 \%$ of the participants $\left(\chi^{2}=15.874, p<0.001\right)$. Patients in both clusters differed statistically significantly by gender $\left(\chi^{2}=17.944, p<0.001\right)$, residence status $\left(\chi^{2}=20.041\right.$, $p<0.001)$ and the number of days spent in the hospital $\left(\chi^{2}=7.991, p=0.018\right)$. The age difference in both clusters was not statistically significant. The group with the most satisfied customers (Cluster 2) can be characterised by a higher number of women, patients for whom 
Latvia is not a country of residence, also proportionally fewer patients who have spent only 1 day in the institution, and more patients who have spent more than 5 days in the institution. Women respondents also showed in all groups of factors a smaller difference between the expected and the perceived outcome, which indicates a connection between satisfaction and determination of the choice of service.

\section{Conclusions}

The results of the study confirm that evaluating patient experience is the key step towards patient-centred health care similar to the proposed assessment models [14-17]. The study supports the application of a patient-centred approach and evaluation of patients' experience in the context of cross-border health care. Regarding the assessment of patient satisfaction, the authors, similar to what has already been discussed in the scientific literature $[18,19]$ conclude that satisfaction is one of the achievable results in the health system and it is linked to patient experience related to the health care service received.

The assessment of the experience of foreign patients in Latvia, using the gap model of service quality, shows that patients evaluated the perceived health care outcome higher than the expected outcome. It occurred in all groups of factors proposed in the study: (1) general travel/destination factors; (2) communication factors; (3) factors related to the choice of service and (4) factors related to the choice of health care institution. The results lead to the conclusion that there is a significant gap in foreign patients' knowledge regarding the possibilities of receiving a high-level service in Latvia.

The study confirms the importance of general travel factors in the context of cross-border care: macro-level factors such as national image, safety and accessibility play important role in attracting foreign consumers. Potential foreign patients significantly lack information to make decisions about Latvia as the destination for health care services.

The study concludes that safety and accessibility of the destination, interpersonal communication - the kindness and responsiveness of personnel, full information about the continuity of service, as well as the affordability of the service play the most significant role in patient satisfaction.

The study indicates the export potential of Latvian medical institutions for technologically sophisticated medical services with highly added benefit - surgery, radiation therapy, dentistry, diagnostic services, etc. The overall satisfaction of foreign patients with the received health care service in Latvia is high: $87.1 \%$ of the patients were completely satisfied, and $12.9 \%$ were partially satisfied. The study confirms that the satisfaction of foreign patients with received health care in Latvia is associated with general travel factors, communication factors and factors influencing the choice of service, such as the assurance of timely provision, medical information exchange, and affordable price. Factors influencing the choice of health care institution play a lesser role in the decision about the choice and overall satisfaction.

\section{References}

[1] M. Wismar, W. Palm, J. Figueras, K. Ernst, E. van Ginneken, World Health Organization / European Observatory on Health Systems and Policies (2011)

[2] N. Lunt, R. Smith, M. Exworthy, S.T. Green. D. Horsfall, \& R. Mannion, Directorate for employment, labour and social affairs, OECD (2014)

[3] BalticCare. Clinics. http://www.balticcare.eu/en/clinics/

[4] The European Union. The European Court of Auditors' special report on EU actionon cross-border health care (2019) 
[5] N. Lunt, P. Carrera, Maturitas 66, 27-32 (2010)

[6] J. Hanefeld, D. Horsfall, N. Lunt, \& R. Smith, PLoSOne 8(10), e70406, (2013)

[7] P.D. Cleary, J. health politics, policy and law 41(4), 677-682 (2016)

[8] R.A. Price, B. Stucky, L. Parast et al. J. Palliative Med. 21(7), 27-29 (2018)

[9] A. Rosiek-Kryszewska, K. Leksowski, IGI Global. 106-119 (2018)

[10] V.A. Zeithaml, M.J. Bitner, D.D. Gremler, McGraw-Hill Education (2017)

[11] A. Parasuraman, L.L. Berry, V.A. Zeithaml, J. Retailing 67(4), 420-450 (1991)

[12] D. Behmane, D. Rutitis, Management Theory and Studies for Rural Business and Infrastructure Development 40(4), 442-454, (2018)

[13] A. Villerusa, D. Behmane, U. Berkis, A. Kokarevica, V. Cauce, Proceedings of the Latvian Academy of Sciences, Section B, Natural Exact and Applied Sciences 73(4), 269-277 (2019)

[14] S. Wilson, J. Dewing, A. Smith, East Sussex Healthcare NHS trust, 12-13(2013)

[15] R. Smarta, Asian Hospital and Healthcare Management 2(39), 47-48 (2017)

[16] A. Tong, S. Jesudason, Best practice \& research clinical obstetrics \& gynaecology, 57(4), 78-86 (2019)

[17] L. Elysia, L. Sharma, L. Bohren, A. Meghan, T. Özge, Bulletin of the World Health organization, 97(8), 564-566 (2019)

[18] M.E. Kruk, A.D. Gage, C. Arsenault, K. Jordan et al. Lancet Glob Health 11(6), 1198-1212 (2018)

[19] A. Timmer, D. de Sordi, E. Menke, J. Peplies et al. Clinical Epidemiology 10(2), 12891305 (2018) 